\title{
Morphological changes in the frog cerebellar cortex after unilateral section of the statoacustic nerve
}

\author{
D. Necchi ${ }^{1}$, E. Scherini ${ }^{1}$, L. Botta ${ }^{2}$, C. Soldani ${ }^{1}$, P. Valli ${ }^{2}$, G. Bernocchi ${ }^{1,3}$
}

${ }^{1}$ Dipartimento di Biologia Animale, Università di Pavia, Pavia, Italy, ${ }^{2}$ Dipartimento di Scienze Fisiologiche-Farmacologiche Molecolari-Cellulari, Università di Pavia, Pavia, Italy and ${ }^{3}$ Istituto di Genetica Molecolare del C.N.R., Pavia, Italy.

Key words: vestibular compensation, amphibian cerebellum, electron microscopy

\section{SUMMARY}

To investigate a possible role of the cerebellum in vestibular compensation that follows a lesion to the vestibular apparatus, the morphological changes of the cerebellar cortex of adult frogs following unilateral statoacustic nerve section was analyzed by means of electron microscopy starting from 3 days after the neurectomy for up to 6 months. On the ipsilateral side, massive abnormality was found in all layers at early postsurgical intervals. This involved both nerve fibers and cell bodies. Fibers often appeared condensed or vacuolated with poorly compacted myelin sheath. Cells had electronlucent and vacuolated cytoplasm to varying extent. Alterations became less conspicuous after 30 days and after 60 days altered nerve cells were no longer present. On the contralateral side, only a few Purkinje and granule cells were affected at early postsurgical stages. This may derive from the fact that, in the frog, some of the vestibular primary afferents reach contralateral cerebellar cortex. At 30 days, alterations had substantially progressed, and at 60 days they involved all the cortical layers. Fiber debris was present in the granular and molecular layers and numerous
Purkinje cells were electrondense and shrunken. This lateness in alteration may be a consequence of the prolonged silence of the vestibular nucleus contralateral to the lesion. At 4 and 6 months the tissue architecture was normal.

\section{INTRODUCTION}

In all tetrapods, lesions to the vestibular system lead to a typical acute syndrome, which is mainly characterized by head and body twisting and locomotion impairement. At a certain interval after the injury, and depending both on the species and on the extent of the lesion, the animal recovers to near normality. This process is referred to as vestibular compensation (Igarashi, 1984).

The vestibular syndrome and compensation have been object of numerous experimental studies (for a review see: Smith and Curthoys, 1989; Dieringer, 1995; Darlington and Smith, 2000), as a model of neural plasticity. However, the plastic phenomena that are at the basis of vestibular compensation are far from being satisfactorily clarified. Most studies aimed at unraveling the mechanism of vestibular compensation have focused on the vestibular 
nuclei, but morphological analyses of the vestibular nuclei in mammals have shown only degenerative phenomena in the nucleus ipsilateral to the lesion (Mugnaini et al., 1967; Gacek et al., 1988).

According to some authors (Putkonen et al., 1977; Courjon et al., 1982), vestibular compensation could be the result of vicarious functioning, i.e., the substitution of labyrinthine with other information from different central nervous system areas. Among these areas, the cerebellum might have a role (Smith and Curthoys, 1989; Darlington and Smith, 2000), as it receives primary and secondary afferents from the vestibular apparatus.

Section of the statoacustic nerve is known to induce the vestibular syndrome (Mugnaini et al., 1967; Gacek et al., 1988; Cass and Goshgarian, 1990; Kunkel and Dieringer, 1994; Gacek and Schoonmaker, 1997; Darlington and Smith, 2000). In the frog, the vestibular syndrome that follows a lesion to the vestibular apparatus is characterized by alterations of the posture and locomotion. The static symptoms recover within 3 days after the lesion. After 15 days, also the dynamic symptoms begin to disappear, and at 30 days the locomotion is normal (Magherini et al., 1981; Dieringer, 1995). In previous studies carried out on the cerebellum of adult frogs after section of the statoacustic nerve, we observed a loss of Purkinje and granule cells at brief intervals from the lesion and, later on, signs of circuitry remodeling (Vignola et al., 1992, 1993). To further investigate the role of the cerebellum in the vestibular compensation process and to correlate the recovery of static and dynamic symptoms with tissue changes and neural plasticity, we undertook an ultrastructural study of the ipsi- and contralateral sides of the frog cerebellar cortex after unilateral section of the statoacustic nerve. Changes were monitored from the beginning of the compensatory phase 3 days after neurectomy up to 6 months. We choose these post-surgical intervals to correlate morphological aspects to well characterized physiological data.

The vestibulo-cerebellar system of the frog has been extensively studied (Hillman, 1969; Llinas et al., 1969; Precht et al., 1974; Sotelo, 1976; Dieringer and Precht, 1979; Cochran et al., 1987; Knopfel, 1987; Reichenberger et al., 1992; Dieringer, 1995; Hiraoka et al., 1995). It consists of primary vestibular fibers that project mainly to the granular layer of auricolar lobe, and secondary vestibular fibers termi- nating in the granular layer of both auricolar lobe and corpus cerebelli, with an occasional branch reaching up to the molecular layer (Honrubia et al; 1985; Kuruvilla et al., 1985; Suarez et al., 1985; Fuller, 1974). In particular, though the basic circuitry is similar to that of mammals, the cerebellum of the frog is much simpler, thus facilitating the analysis of degenerative changes and synaptic remodeling. In addition, since main efferents from vestibular nuclei project to the corpus cerebelli and plastic phenomena can occur in the vestibular nuclei after hemilabirintectomy (Igarashi, 1984), we have focused our attention mainly on the corpus cerebelli.

\section{MATERIALS AND METHODS}

Sixteen adult frogs (Rana esculenta L., purchased from a local dealer) were deeply anesthetized by immersion in $0.1 \%$ MS222 solution (Sandoz, $\mathrm{CH}$ ). The roof of the mouth was opened and the right VIII cranial nerve exposed and severed between Scarpa's ganglion and the brainstem. Eight frogs were sham-operated, i.e. the right VIII nerve exposed, but not severed. Additional 8 frogs were used as controls. At days 3, 15, 30 or 60 the animals (4 operated and 2 sham-operated and 2 control frogs per post-surgical stage) were anesthetized again and perfused intracardially $(1.5 \mathrm{ml} / \mathrm{min}$ for 10 min) with Ringer's solution modified for anurans (composition: $117 \mathrm{mM} \mathrm{NaCl} ; 2.5 \mathrm{mM} \mathrm{KCl} ; 1.2$ $\mathrm{mM} \mathrm{NaHCO}{ }_{3} ; 0.17 \mathrm{mM} \mathrm{NaH}_{2} \mathrm{PO}_{4} ; 1.8 \mathrm{mM} \mathrm{CaCl}_{2}$; $5.5 \mathrm{mM}$ glucose; pH 7.3; Mazzi, 1977) supplemented with heparin (4000 U.I./100 ml). Thereafter, the frogs were perfused for $20 \mathrm{~min}$ with a solution containing $1 \%$ paraformaldehyde and $1 \%$ glutaraldehyde in $0.12 \mathrm{M}$ phosphate buffer, $\mathrm{pH}$ 7.3. At the end of the perfusion period, the whole head was isolated and immersed in the same fixative for $2 \mathrm{~h}$. The cerebellum was then removed and divided in two halves. After washing in phosphate buffer and post-fixation in $1 \%$ aqueous $\mathrm{OsO}_{4}$ for $2 \mathrm{~h}$ at $4^{\circ} \mathrm{C}$, the specimens were dehydrated in ethanol, passed through propylen-oxide and embedded in epoxy resin. Four additional frogs were neurectomized as above and killed after 4 months ( 2 animals) and 6 months (2 animals).

Thin sections of the corpus cerebelli were stained with uranyl acetate and lead citrate and observed with a Zeiss 900 electron microscope. Non-oper- 
ated frogs housed identically to the experimental ones were used as controls for the quality of fixation and embedding procedures.

All experiments reported in this article were conducted in accordance with Italian guidelines of the law 116/92 regarding the care and use of laboratory animals.

\section{Cell counting}

The percent frequency of altered Purkinje cells was calculated separately in the ipsi- and contralateral corpus cerebelli, by counting normal and abnormal cells in semithin sections in double blind fashion. For counting, an area of $10,000 \mu \mathrm{m}^{2}$ was randomly chosen by means of an eyepiece grid. Two fields in at least 6 semithin sections per animal were considered. The sections were selected on the basis that the same cells were not present in two different sections. Since no significant difference (ANOVA test) was found among animals of the same group, percentages $\pm \mathrm{SD}$ were calculated from the whole sample data.

\section{RESULTS}

\section{Normal frogs}

The ultrastructure of the cerebellar cortex in control frogs was as previously described (Hillman, 1969; Sotelo, 1976). A typical Purkinje cell is shown in Fig. 1. No sign of alteration due to inappropriate fixation, like breaks in cell membrane or swelling in endoplasmic reticulum and mitochondria, are present.

\section{Sham-operated frogs}

The cerebellum of the sham-operated frogs was largely similar to that of the controls. However, a slight dilation of the endoplasmic reticulum (ER) was sometimes present in Purkinje cells in the ipsilateral side of 3-day-sham-operated animals. At 15 and 30 days, the tissue architecture was completely normal.

\section{Operated frogs: light microscopy and cell counting}

Semithin sections of the cerebellar cortex of operated frogs revealed alterations in the Purkinje cell layer ipsi- and contralateral to the lesion (Fig. 2a, b). In the 3-day-operated animals, in the ipsilateral side (Fig. 2a), Purkinje cells with pale and apparently empty cytoplasm were evenly distributed throughout the layer. Counting of altered Purkinje cells revealed that the $53.06 \%$ (Fig. 3) of the population was affected. In 15-day-operated frogs, the pattern was similar $(55.63 \%$ of the Purkinje cells appeared altered), while 30 days after the injury, the extent of the abnormalities had decreased and only the $8.84 \%$ of the Purkinje cells showed cytoplasmic changes. At 60 days, the tissue architecture was as in normal frogs and only sporadical Purkinje cells (1.77\%) were altered. After 4 and 6 months the tissue architecture was completely restored.

In the Purkinje cell layer of the contralateral side, we observed cellular changes similar to those described in the ipsilateral side. However, many fewer Purkinje cells $(20.34 \%$ of the population, Fig.2b, 3) were affected than was the case for the neurectomized side. At 15 days, the frequency of abnormal Purkinje cells decreased to $17.01 \%$. After 30 days, the $29.69 \%$ of Purkinje cells appeared altered and at 60 days the affected cells constituted the $43.28 \%$ of the population. No changes were apparent at 4 and 6 months.

Operated frogs, ipsilateral side: electron microscopy

Three days after neurectomy, in the granule cell layer, few fibers showed condensation of the axoplasm and alteration in the myelin sheath, which appeared poorly compacted (Fig. 4a). Some granule cells had vacuolated cytoplasm, with scanty but well preserved mitochondria (Fig. 4b). In the molecular layer, many parallel fibers were swollen and had electronlucent axoplasm. Interneurons showed dilation of the ER and Golgi complex, along with swelling of some of the mitochondria (Fig. 4c). The Purkinje cells showed cytoplasmic changes to varying extent. Some cells had empty, vacuolated, electronlucent cytoplasm, without apparent organization of the few organelles (Fig. 4d). Other cells had electronlucent cytoplasm and, mainly in the peripheral area, the cisternae of both smooth and rough ER were massively distended (Fig. 5). Finally, a few Purkinje cells had undergone dark necrosis (not shown).

Fifteen days after neurectomy the abnormality had progressed further. In the granule cell layer, fibers were surrounded by uncompacted whorls of membranes and many granule cells had empty cytoplasm. There were numerous microglial cells in the process of phagocyting cell debris. Only a few Purkinje cells had a normal healthy appearance. Several 


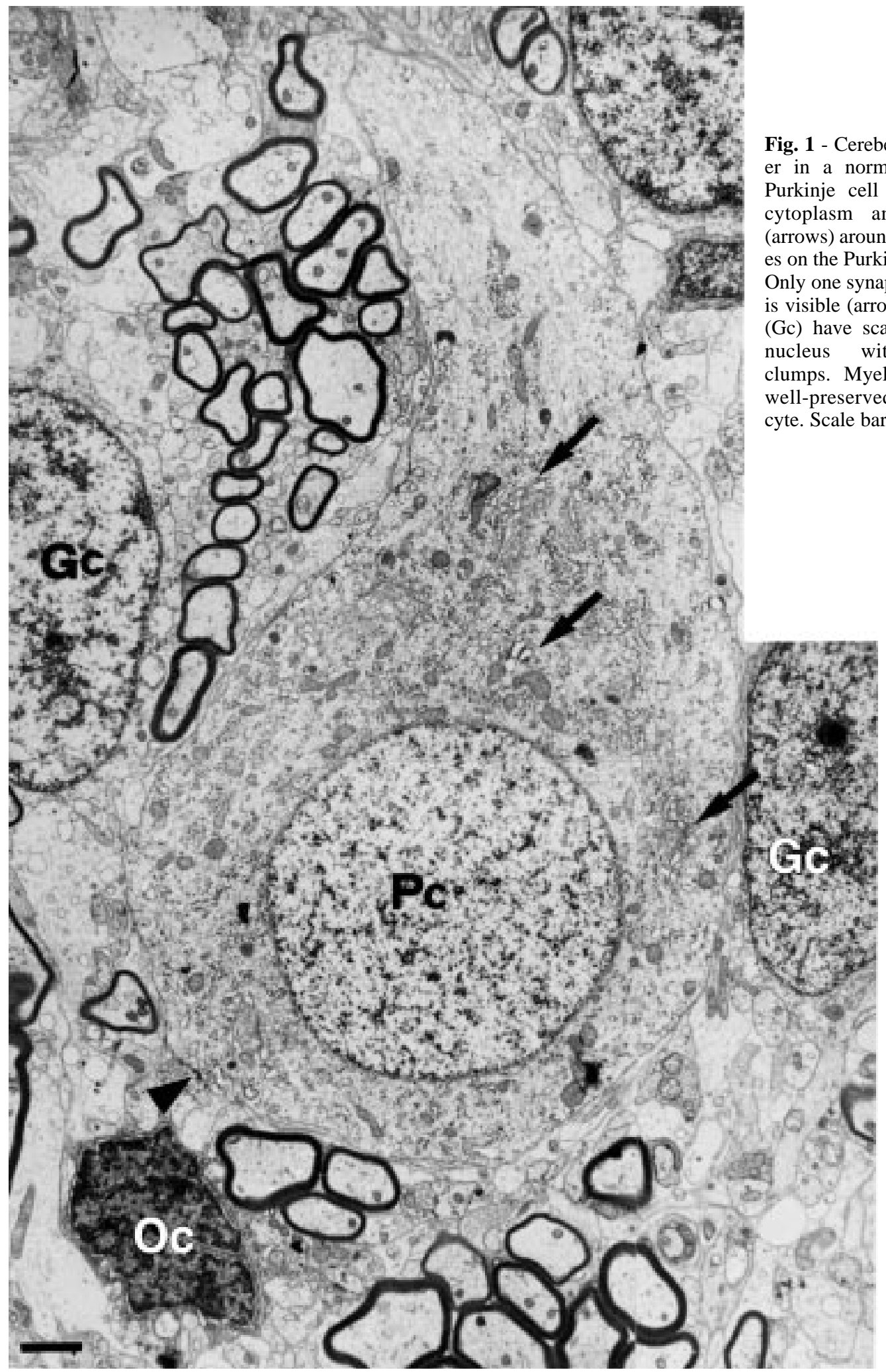



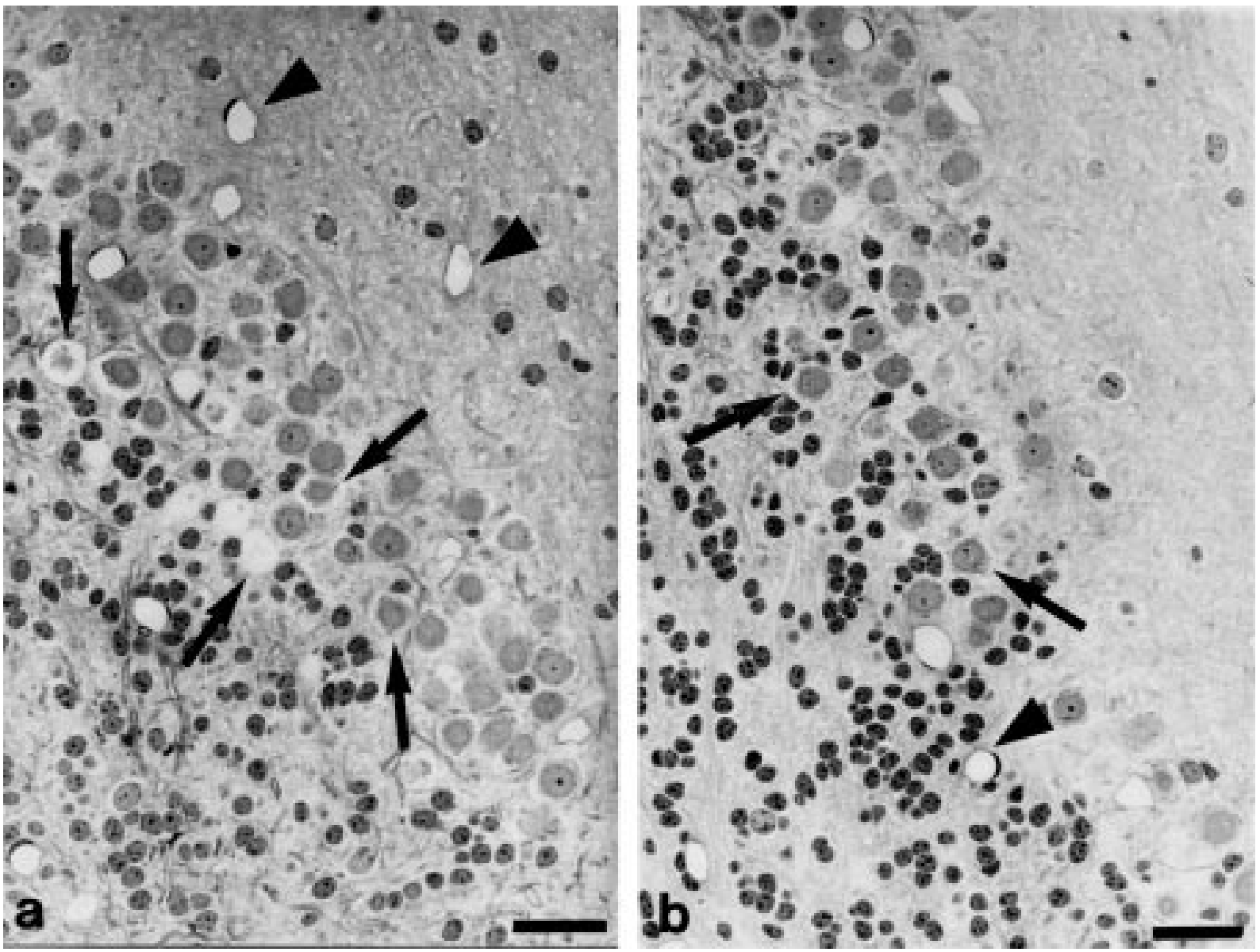

Fig. 2 - Toluidine blue stained semithin section of the cerebellar cortex in a 3-day-operated frog. a) Ipsilateral side. Altered Purkinje cells are evident throughout the layer (arrows). The cytoplasm appears pale and swollen to varying extent. Scale bar: $30 \mu \mathrm{m}$. b) Contralateral side. Few Purkinje cells (arrows) are affected. Scale bar: $30 \mu \mathrm{m}$. Blood capillaries are indicated (arrowheads).

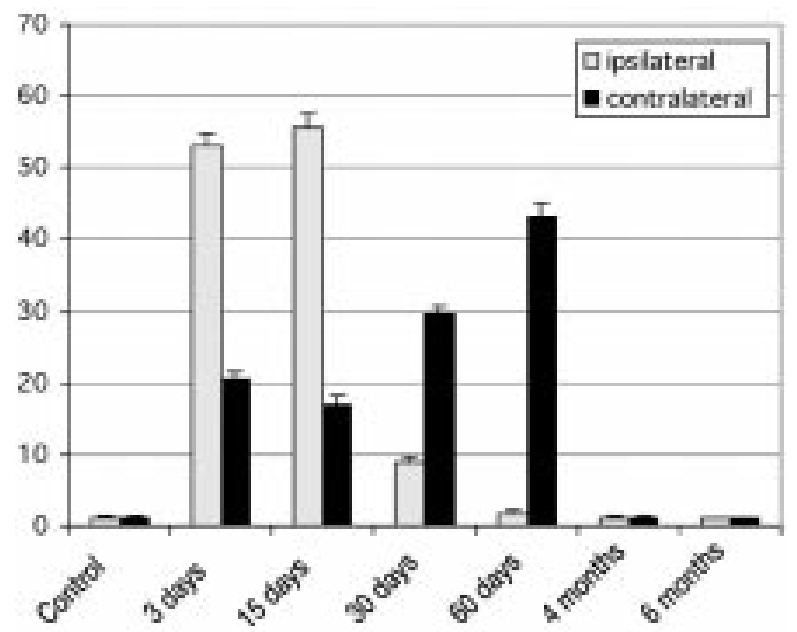

Fig. 3 - Percent frequency of altered Purkinje cells in toluidine blue stained semithin sections. of them had electrondense cytoplasm (Fig. 6a) with bundles of microtubules. The cisternae of the ER were distended and contained flocculent/proteinaceous material. The contour of the cells was irregular, thus suggesting shrinkage. Around the cells, some glial processes were vacuolated.

Thirty days after injury, the extent of the abnormalities had decreased in the granular and Purkinje cell layers, but not in the molecular layer. The granule cell layer contained fewer altered granule cells and fibers, but an increased incidence of microglial cells. In the molecular layer, many parallel fibers were swollen, and Purkinje cell dendrites were electrondense and contained dilated ER cisternae. Climbing fibers also appeared to be altered (Fig. $6 b)$. Several of the interneurons appeared shrunken, and numerous microglial cells were observed near the altered fibers or cells. Electrondense fibers, and 

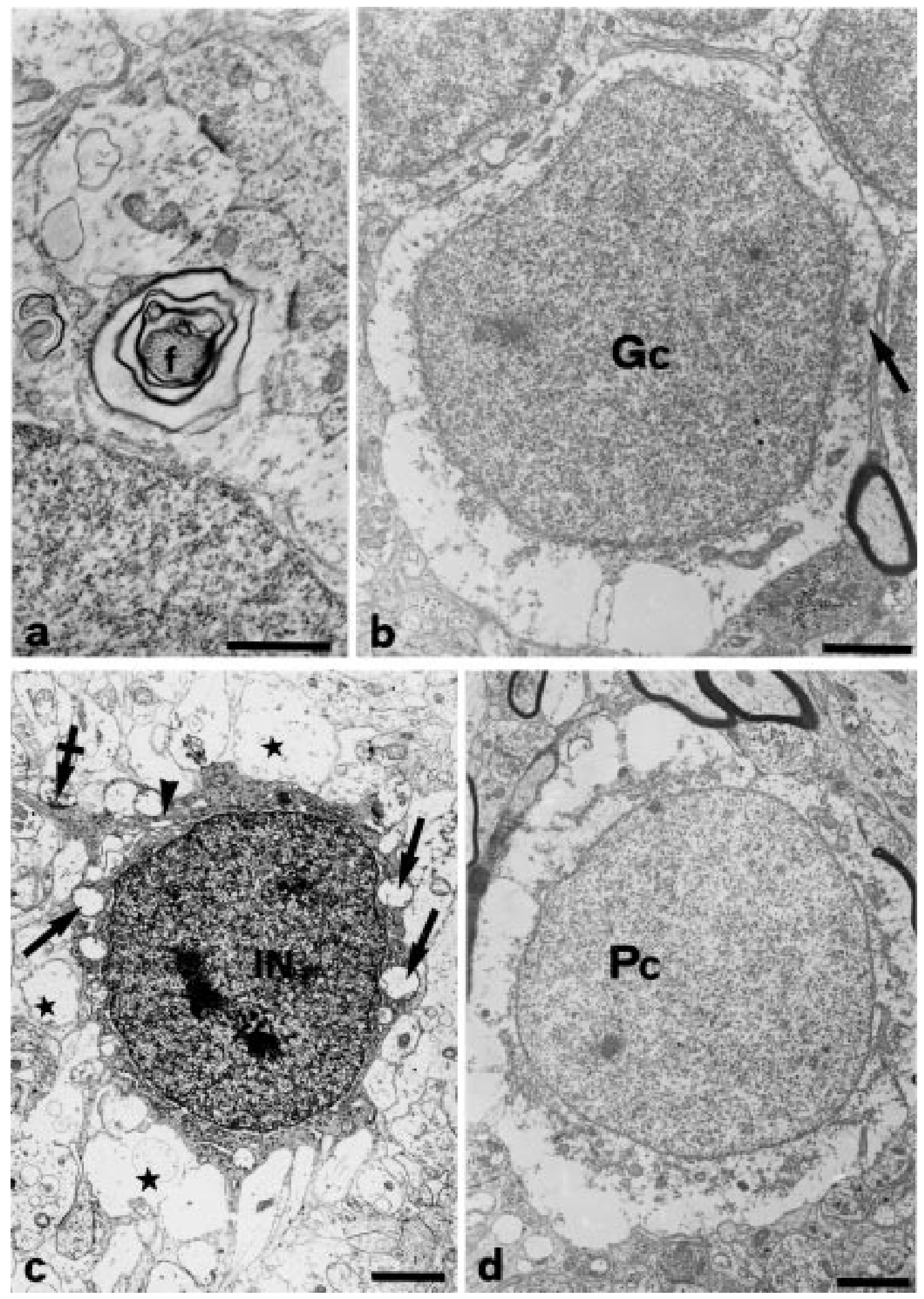

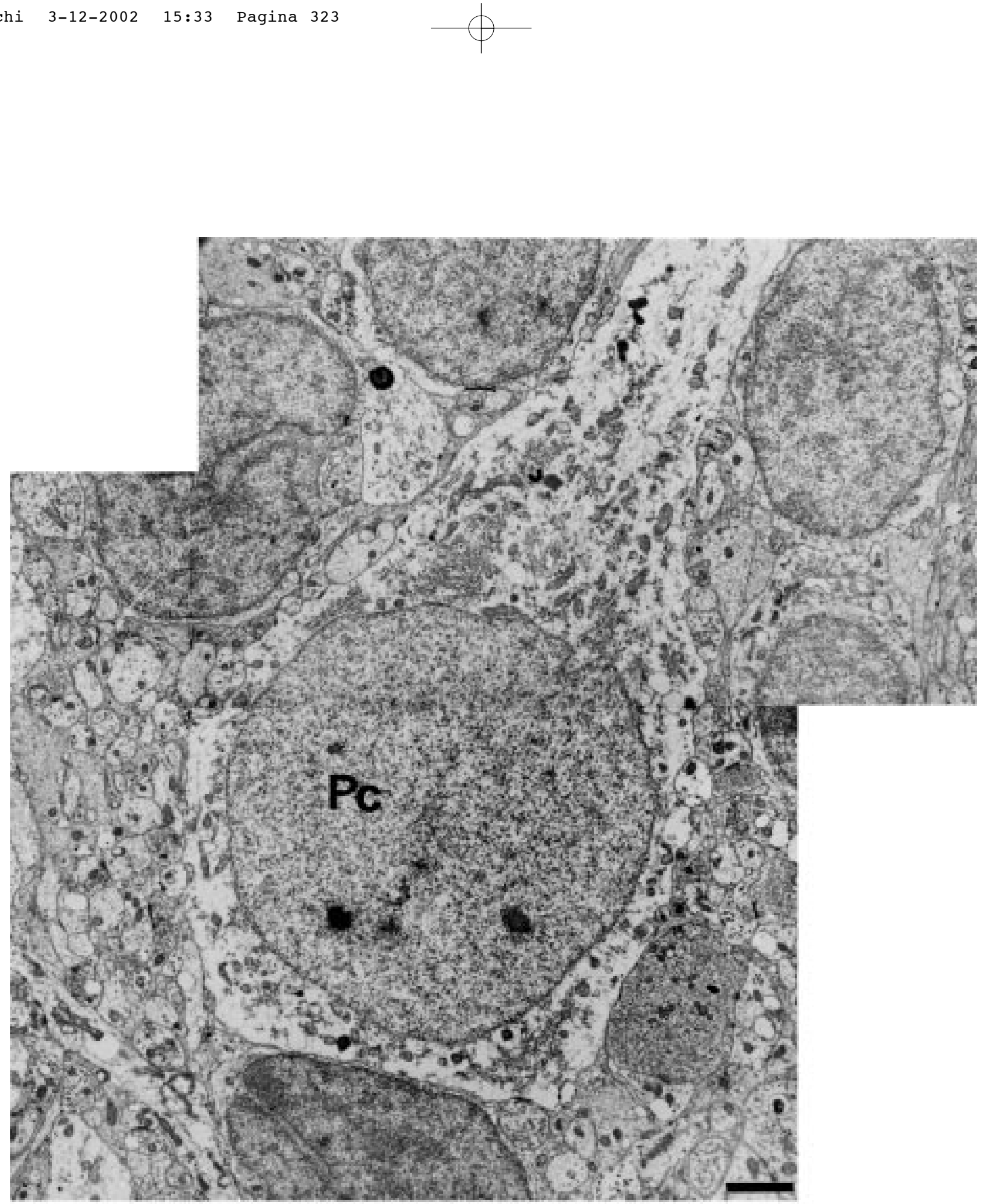

Fig. 5 - 3-day-operated frog, ipsilateral cerebellum. A Purkinje cell $(\mathrm{Pc})$ in which the cytoplasm is electronlucent, with scarce organelles. Granule cells in its surround appear normal. Scale bar: $2 \mu \mathrm{m}$.

Fig. 4 - 3-day-operated frog, ipsilateral cerebellum. a) A fiber (f) in the granule cell layer with dense axoplasm and poorly compacted myelin sheath. Scale bar: $1 \mu \mathrm{m}$. b) Severely swollen granule cell $(\mathrm{Gc})$ with rare but well-preserved mitochondria (arrow). Portions of normal granule cells are included at the top of the microphotograph. A fiber with an intact myelin sheath is also visible in the lower right. Scale bar: $2 \mu \mathrm{m}$. c) In the molecular layer, numerous parallel fibers (stars) are swollen and/or vacuolated. An interneuron (IN) contains electrondense nucleus and has cytoplasm with dilated Golgi apparatus and ER cisternae (arrowhead). The mitochondria are also swollen (arrows). A synapse with a parallel fiber is marked by crossed arrow. Scale bar: $2 \mu \mathrm{m}$. d) A Purkinje cell $(\mathrm{Pc})$ with watery cytoplasm, in which only a few organelles are visible. Note intact fibers at the top of the photograph. Scale bar: $3 \mu \mathrm{m}$. 

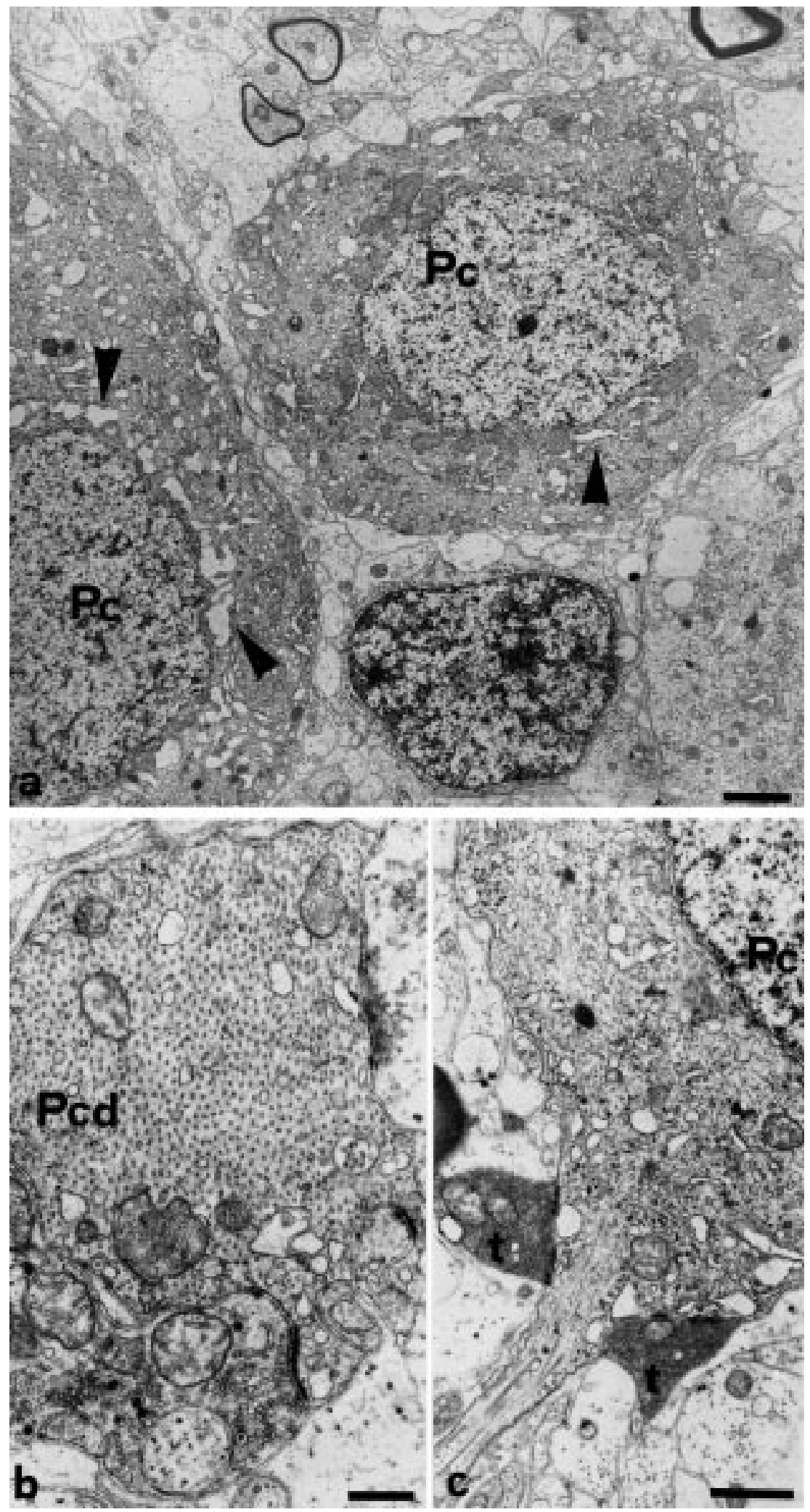

Fig. 6 - Operated frogs, ipsilateral cerebellum. a) 15-day-operated frog. Purkinje cells (Pc) appear to be electrondense, with distended ER cisternae (arrowheads). Scale bar: $2 \mu \mathrm{m} . \mathrm{b})$ 30-day-operated frog. In the molecular layer, a Purkinje cell dendrite (Pcd) contains swollen ER tubules and cytoplasmic matrix of higher electrondensity than normal. The dendritic spine is contacted by a climbing fiber with swollen mitochondria. Scale bar: $0.5 \mu \mathrm{m}$. c) 30 day-operated frog. Degenerating, electrondense nerve cell terminals $(\mathrm{t})$ containing pleomorphic synaptic vesicles contact the emerging axon of a Purkinje cell (Pc). Scale bar: $1 \mu \mathrm{m}$. 
boutons containing pleomorphic vesicles were visible in contact with or close to the initial segment of Purkinje cell axon (Fig. 6c).

At 60 days from neurectomy, the tissue architecture was almost completely restored. Abnormal Purkinje cells and fibers were observed only sporadically.

In 4- and 6-month-operated frogs tissue abnormality was no longer present. Cells, in particular Purkinje neurons, and fibers appeared well preserved.

\section{Operated frogs, contralateral side: electron microscopy}

In the cerebellar contralateral side of the 3-dayoperated frogs, the nerve fibers in the granule cell layer, were normal, but apoptotic cells with peripheral margination of nuclear chromatin and increased cytoplasmic lucency (hydropic changes) were found (Fig. 7a). Microglial cell with cytoplasmic inclusions are present nearby and sometimes engulfanting apoptotic cells (Fig. 7a). In the molecular layer, parallel fibers and interneurons were normal. Although Purkinje cells had dilation of the ER at the cytoplasm periphery, neurons with clear sign of degeneration or necrosis were invariably absent.

At 15 days, the changes were similar to those observed after 3 days, i.e. the situation appeared to be stationary.

In contrast to the ipsilateral side, the contralateral part of the cerebellum of 30-day-operated frogs showed progressing alterations. Some fibers of the granule cell layer had degenerated, and had been engulfed by microglial cells. Although the molecular layer showed a normal appearance, the Purkinje cell layer showed normal cells interspersed with several shrunken and electrondense cells (Fig. 7b).
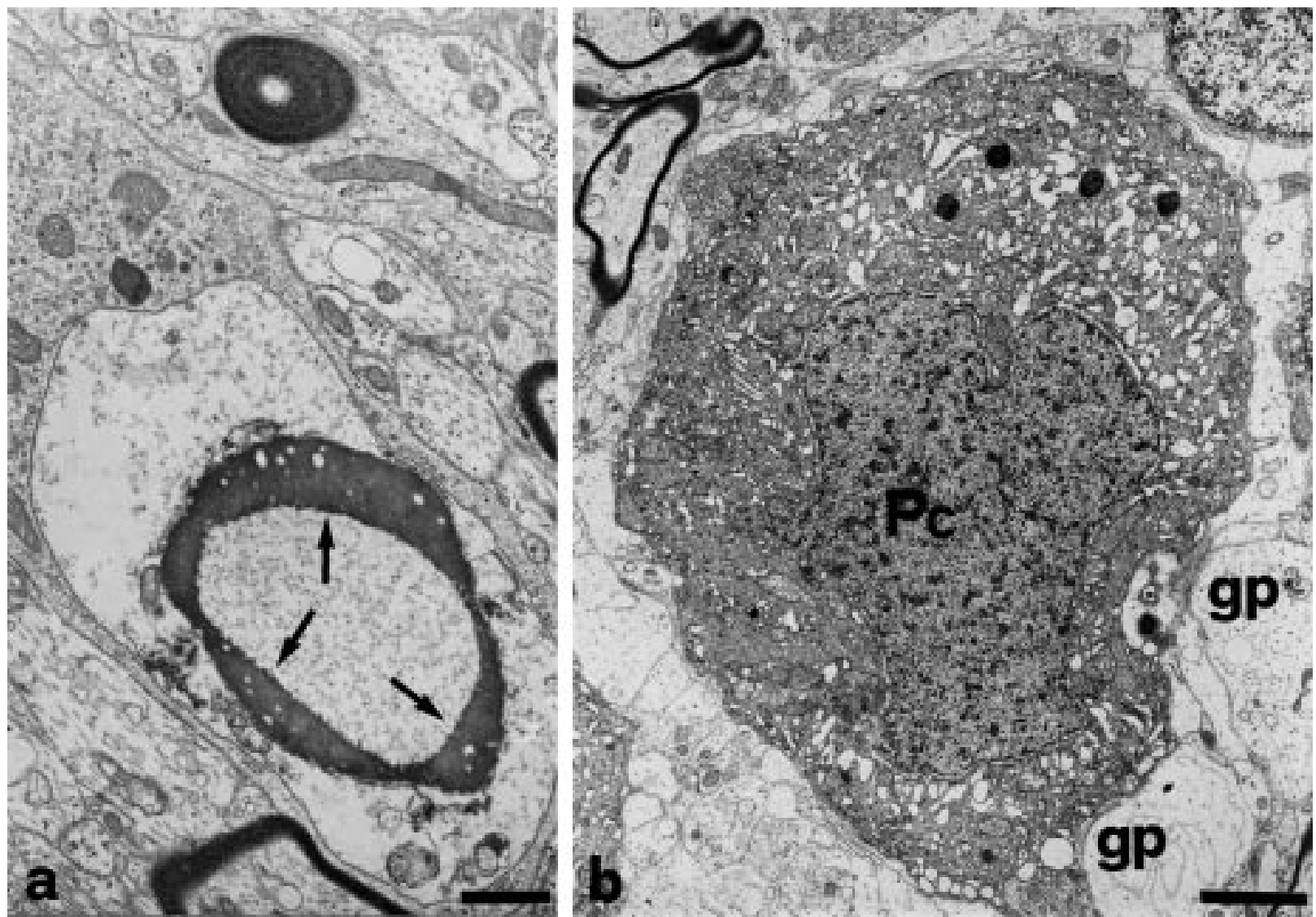

Fig. 7 - Operated frogs, contralateral cerebellum. a) 3-day-operated frog. In the granule cell layer, a small cell presumably granule cell, which shows electronlucent degenerating cytoplasm and margination of chromatin (arrows) in the nucleus, is engulfed by a microglial cell. Scale bar: $1 \mu \mathrm{m}$. b) 30-day-operated frog. Electrondense Purkinje cell (Pc) with dilation of the ER and perinuclear cisterna. The cell is surrounded by swollen glial processes (gp). Scale bar: $3 \mu \mathrm{m}$. 
At 60 days, all cerebellar layers surprisingly showed clearly greater damage than that previously observed. Fiber debris was present in the granular and molecular layers, and several Purkinje cells appeared to be electrondense and shrunken, or had dilated ER cisternae and Golgi apparatus, as observed at the previous post-surgical interval. Glial processes around cells had a watery appearance.

In 4-month- and 6 month-operated frogs, the patterns were similar to those in the ipsilateral side and normal frogs.

\section{DISCUSSION}

The cerebellar side ipsilateral to the neurectomy was mainly affected by changes that suggested degenerative events. These were mostly evident at early post-surgical intervals, and involved all the cerebellar layers and both nerve cells and fibers. At the earliest post-surgical interval considered in this work, only a few altered fiber terminals could be observed. This is in part in contrast with the observation of other authors who described many degenerating pre-terminal fibers in the granular layer 3 days after vestibular nerve section (Hillmann, 1969; Gregory, 1972). It must be considered that our observations are predominantly limited to the corpus cerebelli which receives rare primary vestibular fibers (Fuller, 1974). In addition, the post-surgical interval of 3 days might be excessive for detecting the most of degenerating primary mossy fiber terminals (Kunkel and Dieringer, 1994), which are soon phagocyted. At the same time, the 3-day interval was probably insufficient for the detection of secondary fiber degeneration. Moreover a difference in the technique used may be responsible for the discrepancy of results. In fact, while our analysis was morphological, earlier studies used the Fink-Heimer method, which specifically labels degenerating fibers.

It is likely that granule cells are the first neurons to be involved in damage, and that their involvement is secondary to the degeneration of primary mossy fibers. The alteration of Purkinje cells might be secondary to the partial deafferentiation due to the loss of parallel fibers and, therefore, starts later. In agreement with previous light microscopy data (Vignola et al., 1992), the present results demonstrate that the number of altered Purkinje cells on the ipsilateral side reached a peak (about $50 \%$ of the population) 15 days after neurectomy. After 30 days, only a few Purkinje cells showed alteration, though the total number of cells was greatly decreased (Vignola et $a l .$, 1992), thus indicating that the alteration observed at early intervals from the lesion was irreversible. The occasional Purkinje cells with cytoplasmic changes we observed at this late interval were probably due to alteration of the molecular layer interneurons, most of which were shrunken and electrondense. Dark axonal profiles, probably belonging to molecular layer interneurons, were observed in the vicinity of Purkinje cell bodies and initial axon segments.

Data reported after hemilabyrinthectomy showed that in the frog, the postural disturbances are recovered in as little as 3 days from the injury, and that the locomotory symptoms begin to disappear after 15 days. At 30 days, locomotion is normal (Magherini et al., 1981; Smith and Curthoys, 1989; Dieringer, 1995). The normalization of posture is probably achieved by means of a silencing effect on the contralateral vestibular nucleus neurons and, consequently, on the cerebellum (Igarashi, 1984). It should be noted that the commissural system between the paired vestibular nuclei in the frog is, unlike the equivalent mammal system, mainly excitatory in nature (Will et al., 1988; DeWaele et al., 1995). This factor probably explains the fast postural recovery, in that neural activity in the nucleus contralateral to the lesion is probably depressed rather than increased (Markham and Yagi, 1984).

The above interpretation does not consider the role of the cerebellar side contralateral to the lesion. Here, the results obtained in this study are intriguing. The pattern of abnormality opposed that of the ipsilateral side. As previously found at the light microscopic level (Vignola et al., 1992), at short post-surgical intervals the percentage of altered Purkinje cells (about 20\% of the population) was lower than in the ipsilateral side. These early changes may be due to the degeneration of some afferent fibers, since the frog VIII cranial nerve fibers reach not only the ipsilateral side, but also the contralateral side, albeit in less number (Gregory, 1974; Nieuwenhuys and Opdam, 1976; Montgomery, 1988). In addition, the contralateral changes may be secondary to degeneration of granule cells in the ipsilateral side, which extend their parallel fibers along the entire width of the cerebellum (Llinas et al., 1969; Sotelo, 1976). The contralateral cerebellar 
damage is, at least apparently, rapidly restored, since at post-operative day 15 , changes in comparison with the day 3 stage were not detected. However, observation of the cerebellar contralateral side 30 and, above all, 60 days after the VIII nerve section produced the unexpected finding of distinct tissue abnormality, which extended to all the cerebellar layers. This late cerebellar alteration is not easy to explain. It might be part of the strategy to restore and re-balance neural activity. It is intriguing that this phenomenon occurs after both the vestibular compensation and recovery of the dynamic symptoms are completed. In the cerebellar side contralateral to the lesion, after 4 months, the tissue architecture is normal.

\section{ACKNOWLEDGEMENTS}

The research was supported by Italian Ministry for Universities and Research, grant 9805034767 to E.S. and C.N.R. grants.

We would like to thank Mrs. Paola Veneroni for excellent technical assistance.

\section{REFERENCES}

Cass S.P., and Goshgarian H.G.: Increased glial fibrillary acidic protein immunoreactivity in astrocytes within the lateral vestibular nucleus of the cat following labyrinthectomy and vestibular neurectomy. Ann. Otol. Rhinol. Laryngol. 99, 221227, 1990.

Cochran S.L., Kasic P., and Precht W.: Pharmacological aspects of excitatory synaptic transmission to second-order vestibular neurons in the frog. Synapse 1, 102-123, 1987.

Courjon J.H., Flandrin J.M., Jeannerod M., and Schmid R.: The role of the flocculus in vestibular compensation after hemilabyrinthectomy. Brain Res. 239, 251-257, 1982.

Darlington C.L., and Smith P.F.: Molecular mechanisms of recovery from vestibular damage in mammals: recent advances. Progr. Neurobiol. 62, 313-325, 2000.

De Waele C., Muhlethaler M., and Vidal P.P.: Neurochemistry of the central vestibular pathways. Brain Res. Rev. 20, 24-46, 1995.

Dieringer N.: Vestibular compensation: neural plasticity and its relations to functional recovery after labyrinthine lesions in frogs and other vertebrates. Prog. Neurobiol. 46, 97-129, 1995

Dieringer N., and Precht W.: Mechanism of compensation for vestibular deficits in the frog. I. Modification of the excitatory commissural system. Exp. Brain Res. 36, 311-328, 1979.
Fuller P.M.: Projections of the vestibular nuclear complex in the bullfrog (Rana catesbeiana). Brain Behav. Evol. 10, 157169,1974

Gacek R.R., Lyon M.J., and Schoonmaker J.: Ultrastructural changes in vestibulo-ocular neurons following vestibular neurectomy in the cat. Ann. Otol. Rhinol. Laryngol. 97, 42$51,1988$.

Gacek R.R., and Schoonmaker J.E.: Morphologic changes in the vestibular nerves and nuclei after labyrinthectomy in the cat: a case for the neurotrophin hypothesis in vestibular compensation. Acta Otol. 117, 244-249, 1997.

Gregory K.M.: The stato-acoustic nuclear complex and the nucleus cerebelli of the frog. A Golgi study. Brain Behav. Evol. 10, 146-156, 1974

Hillman D.E.: Morphological organization of frog cerebellum cortex: a light and electron microscopic study. J. Neurophysiol. 32, 818-846, 1969.

Hiraoka I., Suzuki M., Harada Y., Tagashira N., and Takumida M.: Anatomical and physiological characteristics of vestibular ganglion of the bullfrog. Acta Otol. 519, 253-256, 1995.

Honrubia V., Suarez C., Kuruvilla A., and Sitko S.: Central projections of primary vestibular fibers in the bullfrog. III. The anterior semicircular canal afferents. Laryngoscope 95, 1526-1535, 1985.

Igarashi M.: Vestibular compensation. Acta Otol. 406, 78-82, 1984.

Knopfel T.: Evidence for N-methyl-D-aspartic acid receptormediated modulation of the commissural input to central vestibular neurons of the frog. Brain Res. 426, 212-224, 1987.

Kunkel A.W., and Dieringer N.: Morphological and electrophysiological consequences of unilateral pre- versus postganglionic vestibular lesions in the frog. J. Comp. Physiol. 174, 621-632, 1994.

Kuruvilla A., Sitko S., Schwartz I.R., and Honrubia V.: Central projections of primary vestibular fibers in the bullfrog. I. The vestibular nuclei. Laryngoscope 95, 692-707, 1985.

Llinas R., Bloedel J.R., and Hillman D.E.: Functional characterization of neuronal circuitry of frog cerebellum cortex. J. Neurophysiol. 32, 847-870, 1969.

Magherini P.C., Galli R., and Simonini G.M.A.: Compensazione della sindrome da ablazione vestibolare negli Anfibi anuri. Boll. Soc. It. Biol. Sper. 57, 107-108, 1981

Markham C.H, and Yagi T.: Brainstem changes in vestibular compensation. Acta Otol. 406, 83-86, 1984.

Mazzi V.: Manuale di tecniche istologiche ed istochimiche. Piccin, Padova, 1977.

Montgomery N.M.: Projections of the vestibular and cerebellar nuclei in Rana pipiens. Brain Behav. Evol. 31, 82-95, 1988.

Mugnaini E., Walberg F., and Brodal A.: Mode of termination of primary vestibular fibers in the lateral vestibular nucleus. An experimental electron microscopical study in the cat. Exp. Brain Res. 4, 187-211, 1967. 
Nieuwenhuys R., and Opdam P.: Structure of the brain stem. In: Frog neurobiology. (Eds. Llinas, R. and Precht, W.), SpringerVerlag, Berlin, Heidelberg, New York, pp. 824-853, 1976.

Precht W., Richter A., and Osawa S.: Intracellular study of frog's vestibular neurons in relation to the labyrinth and spinal cord. Exp. Brain Res. 19, 377-393, 1974.

Putkonen P.T., Courjon J.H., and Jeannerod M.: Compensation of postural effects of hemilabyrinthectomy in the cat. A sensory substitution process? Exp. Brain Res. 28, 249-257, 1977.

Reichenberger I., Streit P., Ottersen O.P., and Dieringer N.: GABA- and glycine-like immunoreactivities in the cerebellum of the frog. Neurosci. Lett. 154, 89-92, 1993.

Smith P.F., and Curthoys I.S.: Mechanisms of recovery following labyrinthectomy: a review. Brain Res. Rev. 14, 155180, 1989.

Sotelo C.: Morphology of the cerebellar cortex. In: Frog neurobiology. (Eds. Llinas, R. and Precht, W.), Springer-Verlag, Berlin, Heidelberg, New York, pp. 864-891, 1976.
Suarez C., Kuruvilla A., and Sitko S.: Central projections of primary vestibular fibers in the bullfrog. II. Nerve branches from individual receptors. Laryngoscope 95, 1238-1250, 1985.

Vignola C., Scherini E., Valli P., and Bernocchi G.: Experimental approaches to the study of degenerative and regenerative processes in the nervous tissue. I) Morphological changes in the frog cerebellum after unilateral transection of the VIII statoacoustic nerve. J. Hirnforsch. 33, 509-514, 1992.

Vignola C., Valli P., Fasolo A., and Bernocchi G.: Espressione di proteine citoscheletriche nel cervelletto di rana dopo sezione unilaterale dell'VIII nervo statoacustico. Proc. $55^{\circ}$ Congr. Zool. It., p 65, 1993.

Will U., Kortmann H., and Flohr H.: HRP study on structural changes in the commissural fiber system of Rana temporaria following labyrinthectomy. In. Post-lesion neural plasticity. (Ed. Flohr, H), Springer-Verlag, Berlin, pp. 345-355, 1988. 